\title{
Application of the Microstructural Finite Element Alternating Method to assess the impact of specimen size and distributions of contact/residual stress fields on fatigue strength
}

DOI:

10.1016/j.compstruc.2016.10.011

\section{Document Version}

Accepted author manuscript

Link to publication record in Manchester Research Explorer

Citation for published version (APA):

Larrosa, N., Chaves, V., Navarro, A., \& Ainsworth, R. A. (2017). Application of the Microstructural Finite Element Alternating Method to assess the impact of specimen size and distributions of contact/residual stress fields on fatigue strength. Computers \& Structures, 179, 15-26. https://doi.org/10.1016/j.compstruc.2016.10.011

\section{Published in:}

Computers \& Structures

\section{Citing this paper}

Please note that where the full-text provided on Manchester Research Explorer is the Author Accepted Manuscript or Proof version this may differ from the final Published version. If citing, it is advised that you check and use the publisher's definitive version.

\section{General rights}

Copyright and moral rights for the publications made accessible in the Research Explorer are retained by the authors and/or other copyright owners and it is a condition of accessing publications that users recognise and abide by the legal requirements associated with these rights.

\section{Takedown policy}

If you believe that this document breaches copyright please refer to the University of Manchester's Takedown Procedures [http://man.ac.uk/04Y6Bo] or contact uml.scholarlycommunications@manchester.ac.uk providing relevant details, so we can investigate your claim.

\section{OPEN ACCESS}




\title{
Application of the Microstructural Finite Element Alternating Method to assess the impact of specimen size and distributions of contact/residual stress fields on fatigue strength
}

\author{
N.O. Larrosa ${ }^{\mathrm{a}, *}$, V. Chaves ${ }^{\mathrm{b}}$, A. Navarro ${ }^{\mathrm{b}}$, R.A. Ainsworth ${ }^{\mathrm{c}}$ \\ ${ }^{a}$ School of Materials, The University of Manchester, Manchester M13 9PL, United Kingdom \\ b Departamento de Ingeniería Mecánica y Fabricación, Escuela Superior de Ingenieros, Universidad de Sevilla, Camino de los Descubrimientos s/n, 41092 Sevilla, Spain \\ ${ }^{\mathrm{c}}$ School of Mechanical, Aerospace \& Civil Engineering, The University of Manchester, Manchester M13 9PL, United Kingdom
}

\section{A R T I C LE INFO}

Article history:

Received 2 August 2016

Accepted 5 October 2016

Available online xxx

\section{Keywords:}

Alternating method

Short cracks

Distributed dislocation technique

(DDT)

Residual stresses

Fretting fatigue

Fatigue strength

\begin{abstract}
A B S T R A C T
\end{abstract}

\section{Introduction}

Advances in manufacturing processes make possible the release to market of smaller, lighter and more powerful micro-machines and sensors, permit the implementation of innovative tools and components in medical applications, and allow the use of electronic devices made of a few number of crystals, among other applications. These advances also allow a major reduction in the number of manufacturing macroscopic defects in components. In addition, if these defects are present in the component, with the developments in defect detection technologies, quality control may lead to rejection of the part. As a consequence, in some industries only the presence of microscopic defects, of the size of the microstructure of the material is possible. During operation, many of these components are subjected to cyclic load or vibrations, thus facing potential fatigue failure.

Microstructural Fracture Mechanics provides a theoretical foundation for the evidence observed in the early stages of fatigue crack growth tests [1-5], where the Linear Elastic Fracture Mechanics hypothesis is not valid. Some theories have been proposed, seeking to extend fracture mechanics to the regime where cracks have the size of the microstructure.

The understanding and proper modelling of short fatigue crack growth is of great importance for example in micro-components with dimensions of the order of $100 \mu \mathrm{m}$ or less, and in components under

* Corresponding author.

Email address: nicolas.larrosa@manchester.ac.uk (N.O. Larrosa)
High Cycle Fatigue (HCF), where micro-crack initiation and propagation involves about $90 \%$ of the component's total life, among other cases. Hobson [6], Chan and Lankford [7], de los Rios et al. [8], Navarro and de los Rios [9-11] and Hussain et al. [12], have presented pioneering models to tackle the short crack growth behaviour of plain specimens. However, in-service mechanical parts and structures present stress concentrators of different nature.

Several models, based on microstructural fracture mechanics, have been proposed for the analysis of notch components, as proposed by Tanaka and Mura [13], Chapetti [14], Vallellano et al. [15,16] and Chaves and Navarro [17,18].

Most applications of MFM involve cracks that are small compared to the dimensions of the bodies containing them and this allows the use of infinite or semi-infinite solutions, which simplifies the analysis enormously. There are, however, examples of practical interest in which the influence of the 'far' boundaries cannot be neglected. Coronary stents (Fig. 1), microelectronic contacts, micro-moulds and micro-gears, in which at least one of the dimensions is of the order of a few hundred microns, are examples of micro-components that are susceptible to fatigue failure. Residual stress distributions or contact stress fields play a major role in the integrity of these components. These fields are induced either during fabrication, installation or operation and considering their effect in the analysis is paramount for conservative fatigue assessments.

Residual stresses are the result of non-recoverable strains (plasticity), and as a result permanent stresses are induced in the material. Tensile residual stresses, such as those due to machining or welding processes are detrimental as they increase the mean stress value of 


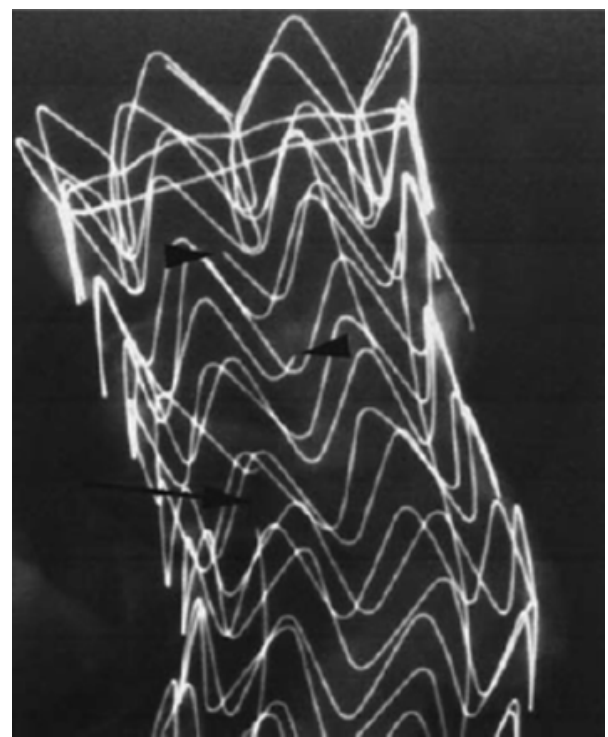

Fig. 1. X-ray image of a stent [19]. Arrows show broken filaments.

the fatigue cycle, whereas compressive residual stresses are generally considered beneficial as they generally reduce mean stress values. Shot peening, laser shock peening, autofrettage and other methods inducing compressive stress on structural surfaces have been demonstrated to be effective for improving the fatigue life and endurance limit of metallic alloys even in the presence of geometrical discontinuities. For example, the fatigue resistance to FOD (Foreign Object Damage) of turbine blades and airfoils is highly influenced not only by the geometry of the notch produced by the impact, but also by the residual stress field produced due to impact and removal of material. The resistance to FOD can be significantly improved by means of one of the techniques mentioned above.

Fretting fatigue, on the other hand, is caused by nucleation and propagation of cracks under the combined action of a cyclic global stress and local stress resulting from contact between two elements. Predicting fretting fatigue crack nucleation and propagation is of great interest in applications where security is critical, such as aircraft, railways and nuclear power plant components. This mechanism drastically reduces the fatigue resistance of engineering structures and mechanical parts [20]. Residual, thermal and contact stresses result in stress gradients in localised areas within the material. The fatigue behaviour of components subjected to these mechanisms can be analysed using methodologies similar to those employed to predict notch fatigue.

This paper deals with the characterization of fatigue failure of components containing very small defects (e.g. cracks). A MFM formulation recently presented by the authors in $[21,22]$ is used to perform fatigue limit calculations of components in which the effects of residual stresses and fretting in the behaviour of finite size components should not be neglected. Comparisons with experimental data and other assessment methods are performed in order to validate the tool for these applications.

\section{Micromechanical model for short crack growth}

For the sake of completeness, the Navarro and de los Rios (NR) microstructural model for short crack fatigue growth assessment is briefly described in this section, although a general and detailed description of the model can be found in [9-11].
In the NR-model, the growth of a small crack is described in terms of successive blocking of the plastic zone at grain boundaries, Fig. 2. Cracks are assumed to be nucleated in second-phase inclusions or particles by the effect of the fracture of particles or their detachment from the matrix. A crack opened in Mode I by a stress $\sigma_{y y}=\sigma$ can be represented by a distribution of edge dislocations with its Burgers vectors normal to the crack plane, as shown in Fig. 3. Each dislocation in the slip plane sees forces due to (1) the applied stresses, (2) the interaction with other dislocations in the same plane and (3) the interaction with other dislocations in parallel planes and with precipitates, second phase particles, etc., which gives rise to friction stresses that oppose the movement of dislocations. A freely-slipping crack is modelled by putting the friction stress $\sigma_{1}$ equal to zero. The friction stress $\sigma_{2}$ in the plastic zone has a value different from zero which is supposed to be a characteristic property of the material. However, within the framework of this work, that is, for the calculation of fatigue limits, $\sigma_{2}$ does not play any role. The reason behind this is that the plastic slip zone ahead of the crack vanishes when the condition giving the maximum required load is reached, i.e. the crack tip has reached the microstructural barrier. Therefore, the particular value assigned to $\sigma_{2}$ is of no consequence for the outcome of the procedure. The friction stress $\sigma_{3}$ in the barrier zone is calculated as part of the solution. For more details the reader should refer to $[17,18]$.

The expression defining the mechanical equilibrium of every dislocation, subjected to the forces described above, leads to a Cauchy singular integral equation which has the dislocation density function [ $f(\xi)]$ as the main unknown:

$$
\int_{-c}^{c} f(\xi) K(x, \xi) d \xi+\frac{\sigma(x)-\sigma_{j}(x)}{A}=0 \quad j=1,2,3
$$

where $A=G b / 2 \pi(1-v)$ (for edge dislocations), $G$ is the shear modulus, $b$ the Burgers vector, $v$ the Poisson's ratio. $\xi$ and $x$ are the

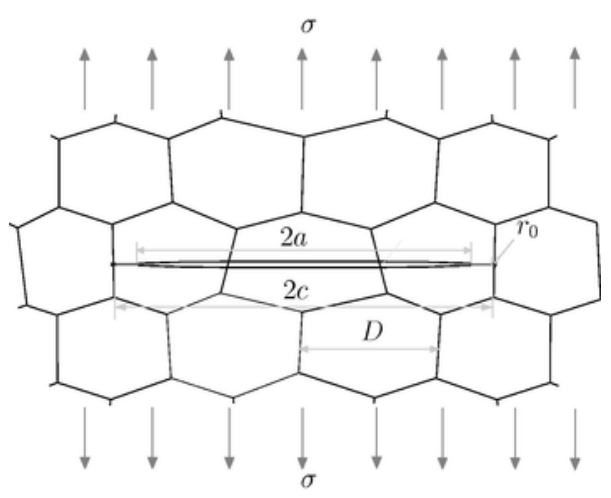

Fig. 2. Crack, plastic zones and barriers in a $2 \mathrm{D}$ polycrystalline infinite plate.

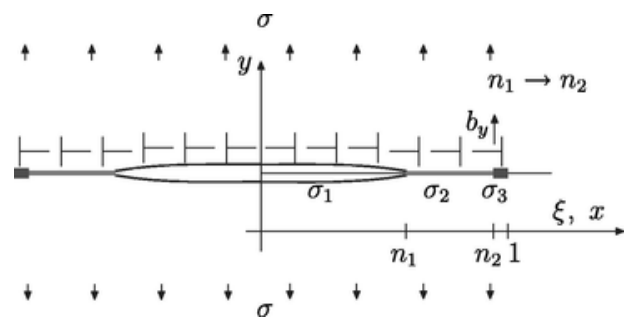

Fig. 3. Dislocation based model by Navarro and de los Rios. 
positions of the source and field points (see Fig. 3), $\sigma(x)$ is the stress induced at the crack line by the external applied load if there were no crack, $\sigma_{j}(x)$ denotes the friction stress at each zone $j$ and $f(\xi)$ is the dislocation density, thus $f(\xi) d \xi$ is the net number of dislocations between $\xi$ and $\xi+d \xi$.

The kernel $K$ models the interactions between the dislocations representing the crack, the plastic and the barrier zones. Since the stress field arising from every dislocation depends upon the geometry of the body and the position of the dislocation within the body, and since the forces between dislocations depends on those fields, the expression of the kernel is geometry dependent $[17,23,24]$. An alternative approach, involves explicit modelling of the contours by means of distributed dislocations, and by means of Bueckner's superposition principle [25] use of infinite or semi-infinite influence functions only to satisfy boundary conditions at the contours. This approach has been applied by many researchers $[23,26,18]$ and proved to be a convenient and accurate way of analysing in-plane problems. Until recently, this strategy was only suitable for problems involving geometries that could be described by explicit expressions, i.e. the equation of equilibrium is defined in terms of geometry-dependent variables (point coordinates along the contour, normal vector at these points and notch length) that are mathematically laborious to be obtained for arbitrarily shaped profiles of unknown mathematical definition. Larrosa et al. $[27,28]$ recently presented an algorithmic modelling tool that can be used to account for true arbitrary shapes modelled with dislocations. However this tool is restricted to geometries in which size effects are not significant. In the MFEAM used in this work, only the kernel for a crack in an infinite solid is used:

$$
K(x, \xi)=\frac{1}{x-\xi}
$$

The solution of Eq. (1) gives the dislocation density $f(\xi)$. For the infinite case and $f(\xi)$ being bounded at both ends, it is obtained by means of the inversion theorem presented by Muskhelishvili [29].

The stress acting upon the barrier $\left(\sigma_{3}\right)$ is calculated through the condition that no infinite stresses should arise in the model. The plastic zone (2) and the barrier (3) are responsible for relaxing the singularity that would otherwise arise at the crack tip. It follows that the solution should be bounded and an existence condition, Eq. (3), is used to calculate the friction stress $\sigma_{3}$ at the barrier:

$$
\left(\sigma_{2}-\sigma_{1}\right) \sin ^{-1} n_{1}+\left(\sigma_{3}-\sigma_{2}\right) \sin ^{-1} n_{2}+\left(\sigma-\sigma_{3}\right) \frac{\pi}{2}=0
$$

giving

$$
\sigma_{3}=\frac{1}{\arccos \left(n_{2}\right)}\left[\left(\sigma_{2}-\sigma_{1}\right) \arcsin \left(n_{1}\right)-\sigma_{2} \arcsin \left(n_{2}\right)+\frac{\sigma \pi}{2}\right]
$$

where $a$ is the crack length, $c=i D / 2, n_{1}=a / c, n_{2}=c /\left(c+r_{0}\right)$ and $D$ and $r_{0}$ are the mean grain size and mean barrier width, respectively.

The details of how this is implemented in the scheme developed for the numerical integration of the equilibrium equation are given elsewhere $[17,18,22]$. For example, for a crack growing in a infinite medium under a uniform applied stress, $\sigma$, the existence condition can be solved (see $[17,21]$ ) and the maximum value of $\sigma_{3}$ is obtained when $n_{1}=n_{2}$, see Fig. 3 for the case of a free-slipping crack $\left(\sigma_{1}=0\right)$ :

$$
\sigma_{3}=\frac{1}{\cos ^{-1}\left(n_{2}\right)} \frac{\pi}{2} \sigma
$$

and assuming $\cos ^{-1} n_{2} \approx\left(2\left(1-n_{2}\right)\right)^{1 / 2} \approx 2\left(r_{0} / D\right)^{1 / 2}$, for a crack reaching the first grain boundary $\left(n_{2} \approx 1\right)$, the following expression is obtained:

$$
\sigma_{3}=\frac{\pi}{4} \sqrt{\frac{D}{r_{0}}} \sigma
$$

Eq. (6) shows that the value of $\sigma_{3}$ is linearly dependent on the value of $\sigma$ as pointed out in [22].

The fatigue limit $\sigma_{F L}$ of a material is given by the minimum applied stress needed to make an edge crack propagate across the first barrier, by the activation of plastic slip beyond it. Therefore, if $\tau_{c}$ is the critical shear stress needed to activate dislocations sources (of the Frank-Read type) in the vicinity in the next grain, the unlocking condition can be expressed in simple terms by assuming the projection of stress $\sigma_{3}$ onto the slip plane and slip direction of the source to obtain the resolved shear stress, using an appropriate crystallographic orientation factor $m_{1}^{*}$. The condition for activating the source and overcoming the barrier is then given by $\sigma_{3}^{1}=m_{1}^{*} \tau_{c}$ and Eq. (6) is adjusted as follows:

$$
\sigma_{3}^{1}=m_{1}^{*} \tau_{c}=\frac{\pi}{4} \sqrt{\frac{D}{r_{0}}} \sigma_{F L}
$$

The same approach can be used $[17,18,22]$ to assess the load required for the crack to span successive microstructural barriers. This is useful as non-propagating cracks have been observed at notch roots [30] and would allow evaluation of the minimum required load to overcome these barriers. The expression for the required stress at the $i$ th barrier, $\sigma_{3}^{i}$, is:

$$
\sigma_{3}^{i}=m_{i}^{*} \tau_{c}=\frac{\pi}{4} \sqrt{\frac{D}{r_{0}}} \sigma_{L i}
$$

where $\sigma_{L i}$ is the minimum applied stress required for growing a crack of length $i D$ in a plain specimen and is obtained from the Kitagawa-Takahashi diagram of the material [31]:

$$
\frac{\sigma_{L i}}{\sigma_{F L}}=\left(\frac{m_{i}^{*}}{m_{1}^{*}}\right) \frac{1}{\sqrt{i}} \quad i=1,3,5, \ldots
$$

The critical value $\sigma_{3 i}=m_{i}^{*} \tau_{c}$ is a material property defining the microstructural barrier strength locally. The parameters in this equation depend only on the material and not on the geometry of the component. Therefore, the remote applied stress producing the stress $\sigma_{3}^{i}$ required to overcome the $i$ th barrier in a notched component, $\sigma_{L i}^{N}$, can be calculated. The value required to overcome the successive barriers 
defines the notch fatigue limit, $\sigma_{F L}^{N}$.

$$
\sigma_{F L}^{N}=\operatorname{Max}\left|\sigma_{L i}^{N}\right|
$$

\section{Microstructural-FEAM algorithm}

The proposed alternating method in [22] is a convenient method to perform fatigue strength assessments of finite size components. The method uses the Schwartz-Neumann [32,33] alternation between a crude and simple finite element solution for an uncracked structure, and the distributed dislocation technique (DDT), Eq. (1), to evaluate the interaction of the crack with the microstructural barriers during growth. The iterative superposition process allows the boundary conditions to be satisfied at the contours of the body. In detail, the procedure works as follows. Consider a 2D body such as that of Fig. 4(a), Problem A, a cracked solid subjected to arbitrary boundary conditions $\vec{t}=\vec{t}_{0}$ and $\vec{u}=\vec{u}_{0}$.

The solution of Problem A can be obtained by iterative combination of the solutions of Problem B and Problem C, shown in Fig. 4:

- Solve the uncracked finite body, Problem B, under the prescribed external boundary conditions $\left(\vec{t}=\vec{t}_{0}\right.$ and $\left.\vec{u}=\vec{u}_{0}\right)$ by using the finite element method (FEM)

- Extract the stresses $\left(\sigma_{\text {crack }}^{i, k}\right)$ at the original crack face location ( $a=i D / 2, i=1$ ) (set $k=0$ as the number of the iterative step).

- The stresses on the crack faces should be zero if the conditions of the original problem are to be fulfilled. This requires addressing Problem C. This problem is solved by means of the DDT, within the NR microstructural model framework. The aim is to obtain the required dislocation density $f^{i, k}(\xi)$ that makes stresses $\left(\sigma_{\text {crack }}^{i, k}, k=0\right)$ vanish. The numerical implementation of the method also gives the first estimate of $\sigma_{3}^{i, k}$ produced by the crack of length $a=i D / 2$ acting upon the microstructural barrier.

Clearly, adding the solution of problems B to that of Problem C does not satisfy the boundary conditions of Problem A at the contours. To achieve this an iterative algorithm is implemented involving the following steps (see Fig. 4(b)).

(1) The stress and displacement fields resulting from the dislocation distribution $f^{i, k}(\xi)$ on the fictitious boundary $\Gamma^{\prime}$ are calculated from:

$$
\begin{aligned}
& \sigma_{x x}^{i, k}(x, y)=\frac{2 \mu}{\pi(\kappa+1)} \int_{-c}^{c}\left(f_{x}^{, k}(\xi) K_{x x x}(x, y, \xi, 0)+f_{y}^{j, k}(\xi) K_{y x x}(x, y, \xi, 0\right. \\
& \sigma_{x y}^{i, k}(x, y)=\frac{2 \mu}{\pi(\kappa+1)} \int_{-c}^{c}\left(f_{x}^{i, k}(\xi) K_{x x y}(x, y, \xi, 0)+f_{y}^{j, k}(\xi) K_{y x y}(x, y, \xi, 0\right. \\
& \sigma_{y y}^{i, k}(x, y)=\frac{2 \mu}{\pi(\kappa+1)} \int_{-c}^{c}\left(f_{x}^{i, k}(\xi) K_{x y y}(x, y, \xi, 0)+f_{y}^{j, k}(\xi) K_{y y y}(x, y, \xi, 0\right.
\end{aligned}
$$

$$
\begin{aligned}
& u_{x}^{i, k}(x, y)=\frac{1}{2 \pi(\kappa+1)} \int_{-c}^{c}\left(f_{x}^{i, k}(\xi) U_{x x}(x, y, \xi, 0)+f_{y}^{i, k}(\xi) U_{x y}(x, y, \xi, 0)\right. \\
& u_{y}^{i, k}(x, y)=\frac{1}{2 \pi(\kappa+1)} \int_{-c}^{c}\left(f_{x}^{j, k}(\xi) U_{x y}(x, y, \xi, 0)+f_{y}^{, k}(\xi) U_{y y}(x, y, \xi, 0)\right.
\end{aligned}
$$

where $K_{r s t}$ and $U_{r s}(r, s, t=x, y)$ are the stress and displacement influence functions, respectively. These functions represent the effect of a dislocation located in the range $|\xi| \leqslant c$ at a given coordinate point $(x, y)$. The expressions for $K_{r s t}$ and $U_{r s}$ can be found in the literature [34].

(2) The corrective tensile vector $\vec{t}_{d}^{k}$ is calculated:

$$
\vec{t}_{d}^{k}=\sigma_{i j}^{k} \cdot \vec{n}
$$

and the displacements $\vec{u}_{d}^{k}$ are defined as $\vec{u}_{d}^{k}=\vec{u}\left(u_{x}^{k}, u_{y}^{k}\right)$

(3) The algorithm makes $k=k+1$. The fields $\vec{t}_{d}^{k-1}$ and $\vec{u}_{d}^{k-1}$ are subtracted from the original boundary conditions, obtaining the modified fields $\vec{t}_{k}$ and $\vec{u}_{k}$.

$$
\begin{aligned}
& \vec{t}_{k}=\vec{t}_{0}-\vec{t}_{d}^{k-1} \\
& \vec{u}_{k}=\vec{u}_{0}-\vec{u}_{d}^{k-1}
\end{aligned}
$$

(4) The modified fields $\vec{t}_{k}$ and $\vec{u}_{k}$ obtained from Eqs. (17) and (18) are applied to the boundary of the uncracked finite body and the problem is solved with the aid of the Finite Element Method (FEM). Once more, the stresses along the crack line, $\left(\sigma_{\text {crack }}^{k}\right.$, $k=1)$, are obtained.

(5) The problem of the infinite body with a finite crack is addressed and the stresses $\sigma_{\text {crack }}^{k}$ calculated in the previous step are applied to the crack sides. Once again, the dislocation distribution on the crack line, $f^{i, k}(\xi)$ and parameter $\sigma_{3}^{i, k}$ in the NR model at the barrier $i$ (e.g. a grain boundary) are calculated.

(6) The convergence criterion of the MFEAM is expressed in terms of the overall pressure on the crack line. The integral of residual pressures in the crack zone is defined as:

$$
P^{k}=\int_{-c}^{c} \sigma_{c r a c k}^{k} \cdot \vec{n} \cdot d \xi
$$

Finally, the termination criterion is as follows:

$$
\left\{\begin{array}{l}
I F \text { TOL }<10^{-3} \rightarrow \text { STOP } \\
\text { ELSE } \rightarrow k=k+1, \text { Go to }(1)
\end{array}\right.
$$




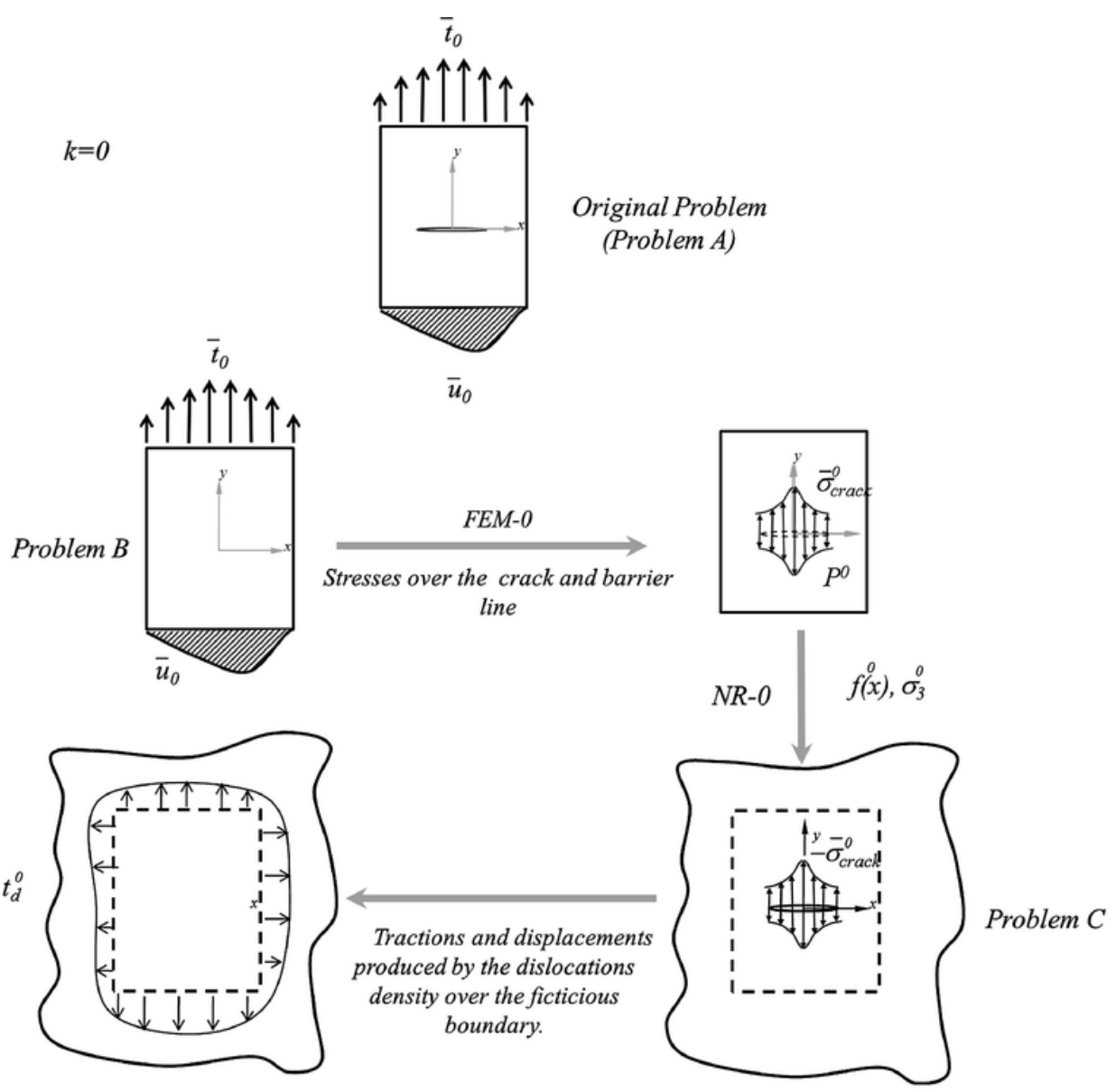

(a) Fist calculation step.

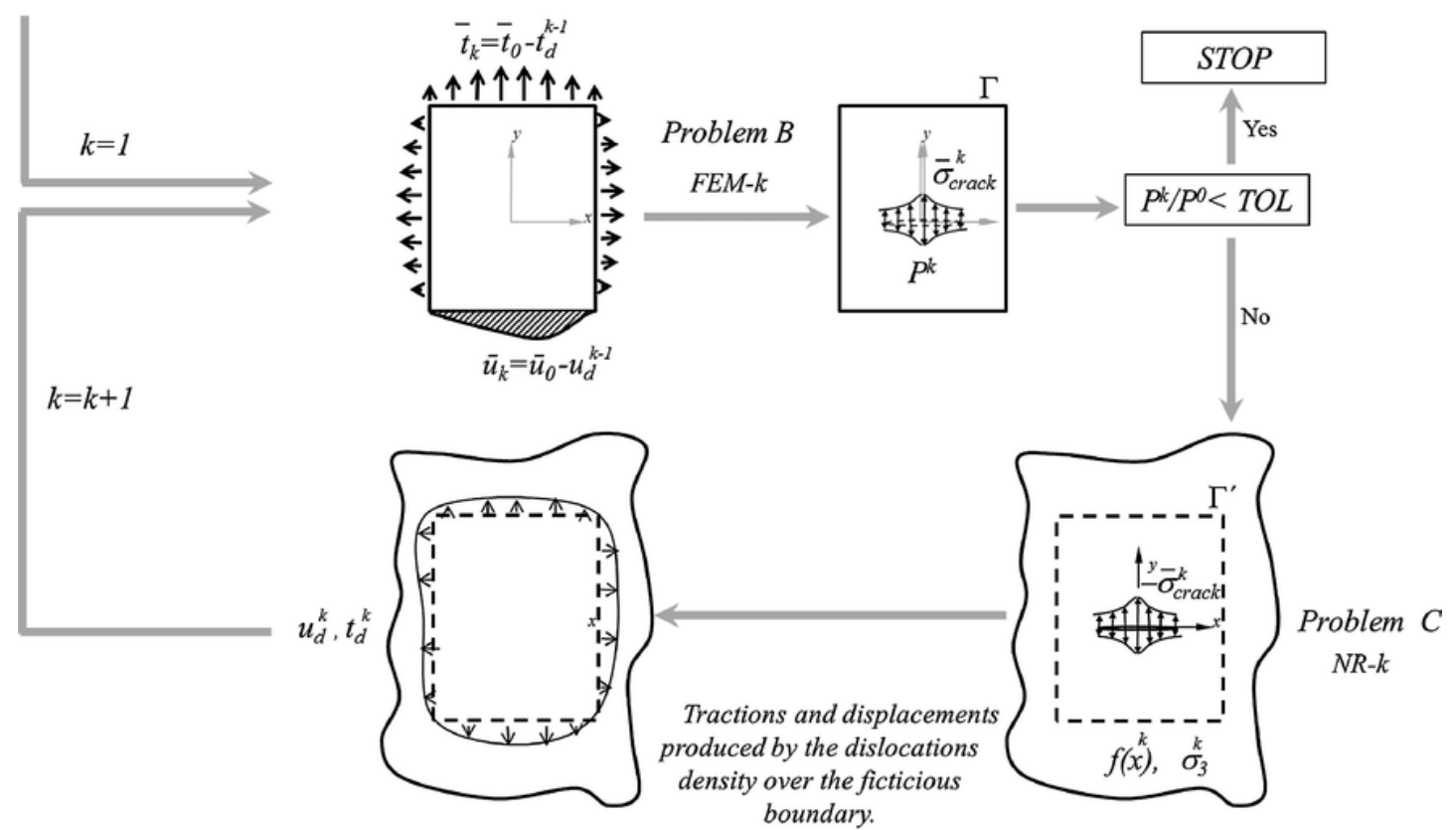

(b) Iterative procedure

Fig. 4. MFEAM schematic description. 
where $T O L$ is given by:

$$
T O L=\frac{P^{k}}{P^{1}}=\frac{\int_{-c}^{c} \sigma_{c r a c k}^{k} \cdot \vec{n} \cdot d \xi}{\int_{-c}^{c} \sigma_{c r a c k}^{1} \cdot \vec{n} \cdot d \xi}
$$

The previous iterative scheme is repeated until convergence is reached, providing the value of the stress at the barrier, $\sigma_{3}^{i}$. If the boundary conditions are just expressed in term of stresses, as is the case when the model is used for comparison with fatigue tests under load control, then there is a linear relationship between the stress at the barrier and the applied stress, as previously explained. The applied stress can be simply scaled until the stress at the barrier reaches the critical value, providing the value of $\sigma_{L i}^{N}$, which is the applied load required to overcome the first barrier in the notched component. Then, the method is repeated for $i=3,5,7, \ldots$ so that the successive values of $\sigma_{3}^{i}$ are obtained, and therefore, the successive $\sigma_{L i}^{N}$. The maximum value of $\sigma_{L i}^{N}$ is the notch fatigue limit $\sigma_{F L}^{N}$.

\section{Results and discussion}

The algorithm described above has been implemented in the Abaqus numerical environment [35], within the user subroutines UTRACLOAD and DISP to apply surface tractions and displacements, respectively. The displacements $\vec{u}_{k}$ are calculated and applied by DISP to the nodes of the finite elements with displacement boundary conditions in Problem A. On the contrary, over elements with loading boundary conditions or with no boundary conditions defined, the traction vector $\vec{t}_{d}^{k}$ is calculated and applied to the Gauss points subroutine UTRACLOAD. The algorithm is coded in Fortran 90 and implemented on a High Performance Computing Server. Three examples showing the capabilities of the method and discussions of the results are provided below. For details of the numerical integration procedure and the implementation of the numerical scheme within Abaqus, reference can be made to [21].

\subsection{Analysis of fretting fatigue behaviour under spherical contact}

Contact is one mechanism for transmitting load between solids and Fretting Fatigue (FF) failure can affect a wide variety of mechanical components. The purpose of the present example is to show the potential use of the proposed method for the analysis of problems involving FF. Fretting fatigue is a superficial damage phenomenon that produces degradation of the mechanical properties of a component due to both high local stresses arising from the elements in contact and stresses due to the action of the applied cyclic load.

It is accepted in the literature [36,37] that contact stresses are the main driver for fretting fatigue failure. These stresses can dramatically reduce the fatigue resistance of a mechanical component, compared to pure fatigue conditions. It is well-known that crack initiation under FF conditions occurs at the trailing edge stick-slip zone, where the highest contact stresses take place. One of the classical ways of predicting the FF strength of a mechanical system [38-41] is to treat the stress state produced by the mechanical contact in a similar way to that produced by notches. These methods consider the stresses around the crack initiation zone, either in an area or a volume, and implement a fretting fatigue criterion to determine the failure of the component.

Following this kind of approaches and considering that the crack/ contact problem can be assumed to be uncoupled (the presence of the crack has a negligible effect over the contact pressure distribution) [42], it is possible to solve the crack and the contact problems separately, which conveniently fits with the MFEAM solution strategy.

In this example, the MFEAM is used to predict the FF behaviour of an Al-7076-T6 alloy under four different loading conditions, reported by Vallellano et al. [43] in a exhaustive experimental and numerical FF analysis. For the present analysis, the crack is considered to grow in the normal direction to the contact surface as it has been observed that the crack propagation path forms an angle of about $80^{\circ}$ with the contact surface [43].

The mechanical properties of the material are shown in Table 1 and the expression proposed by Vallellano for the evolution of fatigue strength with crack length is used as an approximation of the Kitagawa-Takahashi [31] diagram, which is used to estimate $\frac{m_{i}^{*}}{m_{1}^{*}}$, in Eq. (2):

$$
\sigma_{L i}=\sigma_{F L} \frac{\sqrt{a_{0}}}{\left[(i D / 2)^{f}+\left(a_{0}\right)^{f}-(D / 2)^{f}\right]^{\frac{1}{2 f}}}
$$

where $f=2.5$ and $a_{0}=\frac{1}{\pi}\left(\frac{K_{t h}}{\sigma_{F L}}\right)^{2}$ is the El Haddad's short crack parameter. Note that this parameter is equally defined as the critical distance $(L)$ used in the Point Method as re-characterised by Taylor [44].

The different loading test configurations are presented in Table 2.

For the sake of simplicity, the mechanical properties of the bodies in contact are identical in order to avoid relative slip due to Poisson effects, which allows the assumption that the normal and the tangential problems are uncoupled.

Contact between surfaces is modelled implicitly but introducing the Hertzian expressions for the stress fields produced by a normal load $N$. When the component is also subjected to a remote cyclic load $(P)$, which produces a bulk stress $\sigma$, a tangential in-phase force $Q($ $Q<\mu N)$ is induced, as depicted in Fig. 5, and causes an eccentricity $e$ of the stick region, enlarging the slip region at the trailing edge of contact and reducing it at the leading edge. The displacement $(e)$ of the stick zone increases the local stress field in the vicinity of the

Table 1

\begin{tabular}{|c|c|c|c|c|}
\hline $\begin{array}{l}\text { Young's } \\
\text { Modulus E } \\
(\mathrm{GPa})\end{array}$ & $\begin{array}{l}\text { Plain fatigue limit } \sigma_{F L} \\
(\mathrm{MPa})\left(10^{6} \text { cycles }\right)\end{array}$ & $\begin{array}{l}\text { Poisson's } \\
\text { ratio }\end{array}$ & $\begin{array}{l}K_{t h} \\
(\mathrm{MPa} \\
\sqrt{\mathrm{m}} \\
)\end{array}$ & $\begin{array}{l}\text { Average grain } \\
\text { size } D(\mu \mathrm{m})\end{array}$ \\
\hline 71 & 214 & 0.3 & 2 & 35 \\
\hline
\end{tabular}

Physical and mechanical properties of Al-7075-T6 alloy [43].

Table 2

Loading configuration of the different numerical FF tests performed [43].

\begin{tabular}{llll}
\hline Test & $N(\mathrm{~N})$ & $Q(\mathrm{~N})$ & $\sigma(\boldsymbol{P} / \boldsymbol{A})(\mathrm{MPa})$ \\
\hline T11 & 12.5 & \pm 15 & \pm 83 \\
T16 & 13.9 & \pm 10 & \pm 83 \\
T18 & 7.31 & \pm 6.6 & \pm 83 \\
T31 & 12.0 & \pm 9 & \pm 83 \\
\hline
\end{tabular}




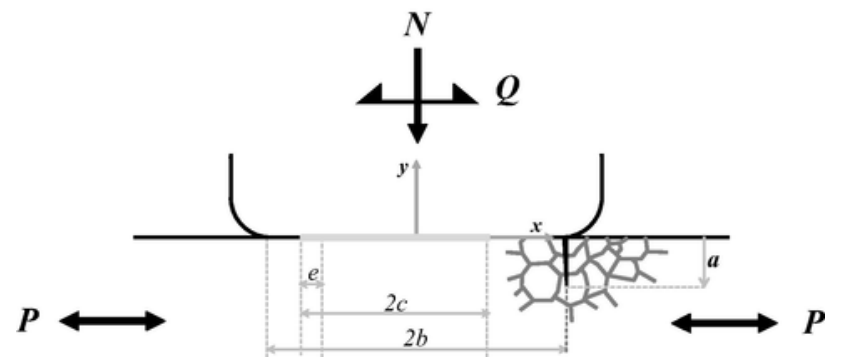

Fig. 5. Schematic view of the loads applied to the spherical contact pair.

crack, reducing the fretting fatigue resistance of the component. The effect of eccentricity of the stick zone is taken into account in the present analysis.

Expressions for the approximation of the stress fields at any point in a zone of spherical contact were proposed by different researchers. In this case, the same expressions used in [43] are implemented into the subroutine UTRACLOAD from the Abaqus subroutine library to apply the normal and tangential stress distributions at the surfaces, as follows:

$$
\begin{aligned}
& p(x)=\frac{3 N}{2 \pi b^{2}}\left(1-\frac{x^{2}}{b^{2}}\right)^{\frac{1}{2}} \\
& q(x)=\frac{3 N \mu}{2 \pi b^{2}}\left(1-\frac{x^{2}}{b^{2}}\right)^{\frac{1}{2}} \quad c \leqslant x \leqslant b \\
& q(x)=\frac{3 N}{2 \pi b^{2}}\left[\left(1-\frac{x^{2}}{b^{2}}\right)^{\frac{1}{2}}-\frac{c}{b}\left(1-\frac{x^{2}}{c^{2}}\right)^{\frac{1}{2}}\right] \quad 0 \leqslant x<c
\end{aligned}
$$

where $b$ is the contact zone radius which is approximated as:

$$
b=\left(\frac{3 N R}{4 E^{*}}\right)^{\frac{1}{3}}
$$

and $c$ is the stick zone size which is approximated as:

$$
\frac{c}{b}=\left(1-\frac{Q}{\mu N}\right)^{\frac{1}{3}}
$$

In the former expressions $R$ is the sphere radius, which for the present study is $25.4 \mathrm{~mm}$, and $E^{*}$ for identical material properties of the contacting bodies is given by:

$$
E^{*}=2\left(\frac{1-v^{2}}{E}\right)
$$

where $E$ is Young's modulus and $v$ is Poisson's ratio of the aluminium alloy under analysis. Fig. 6 shows the pressure distribution obtained from the Hertzian expressions.

If the eccentricity in the stick zone is considered, expressions (24) and (25) are re-written as follows:

$$
\begin{aligned}
& q(x)=\frac{3 N \mu}{2 \pi b^{2}}\left(1-\frac{x^{2}}{b^{2}}\right)^{\frac{1}{2}} \quad c \leqslant x_{e} \text { and } x \leqslant b \\
& q(x)=\frac{3 N}{2 \pi b^{2}}\left[\left(1-\frac{x^{2}}{b^{2}}\right)^{\frac{1}{2}}-\frac{c}{b}\left(1-\frac{x_{e}^{2}}{c^{2}}\right)^{\frac{1}{2}}\right] 0 \leqslant x_{e}<c
\end{aligned}
$$

where $x_{e}=|x-e|$. An approximation for the eccentricity $e$ can be calculated by setting the relative displacement at the stick zone to zero. Assuming plane strain conditions:

$$
e=\frac{(1-v)}{(4-3 v)} \frac{4 b \sigma}{\pi \mu p(0)}
$$

Fig. 7 shows the normal and tangential stress distributions applied to the contact surface of the FEM model for the different tests considered, when the eccentricity produced by the remote load $(P)$ is considered.

The numerical results obtained with MFEAM are presented in Fig. 8, where $\sigma_{L i}^{N} / \sigma$, the dimensionless external applied load needed to overcome the successive microstructural barriers is plotted. If $\operatorname{Max}\left|\sigma_{L i}^{N} / \sigma\right|<1$, then the external cyclic load produces fatigue failure. However, if $\operatorname{Max}\left|\sigma_{L i}^{N} / \sigma\right| \geqslant 1$ then the minimum applied load needed for the specimen to fail has not been reached, and failure does not occur. Note that in all cases the strongest microstructural barrier is the first one. Comparisons with experimental and numerical data are performed for validation purposes. Details of the fatigue test and the numerical methods used to compare the MFEAM results can be found in Vallellano et al. [43]. Table 3 shows the experimental results and the estimations of the different models. It is shown that the MFEAM failure estimations are highly consistent with the experimental results irrespective of whether $e$ is considered or not. Only for the T31 test, in which eccentricity in the stick zone is considered, does the method predicts an erroneous behaviour. However, the prediction is conservative and the error is very small $\left(\sigma_{L i}^{N} / \sigma=1.007\right)$. Again, it is expected that better results should be achieved by counting with the experimental Kitagawa-Takahashi diagram.

In summary, the fretting fatigue behaviour of an aluminium alloy under spherical contact has been analysed. Despite the limitations of the method and the assumptions made in the analysis, the predictions of the proposed tool are in good agreement with Hertzian experiments and the predictions of other established methods. Fretting fatigue is analysed in the same way as notch fatigue and, within the range of the cases of the present study, it is fully addressed by the stress concentration that occurs due to contact between surfaces.

\subsection{Plain micro-scale wires}

In this case, we calculate the fatigue strength of AISI 316L micro-scale wires and provide comparisons with the experimental results for push-pull tests reported by Wiersma [45-47]. For comparison purposes, other methodologies are also applied: Peterson's formula, the Point Method (PM) and the numerical implementation of the NR model as described in [18]. The material properties are given in Table 4. Details of the fabrication and testing of the wires can be found in [45]. 


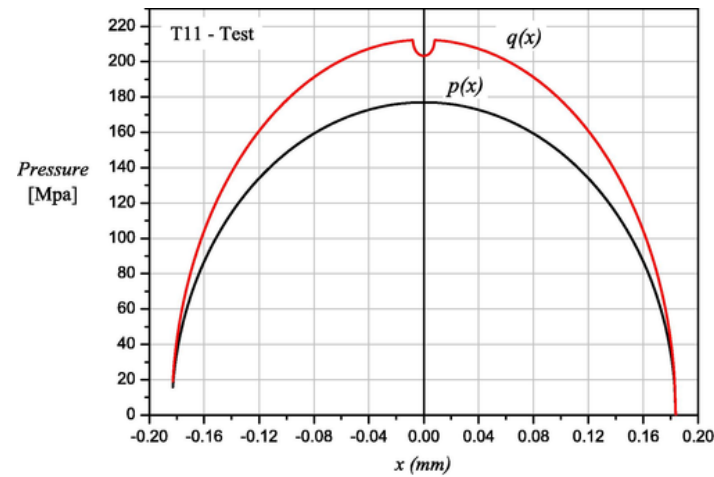

(a) T11 test

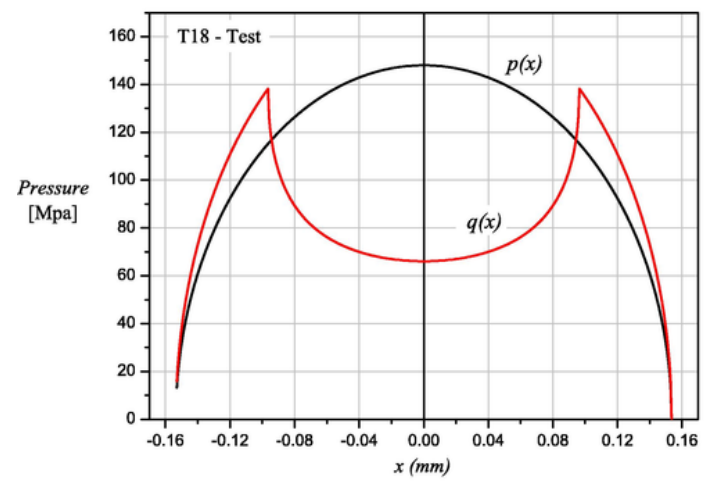

(c) T18 test

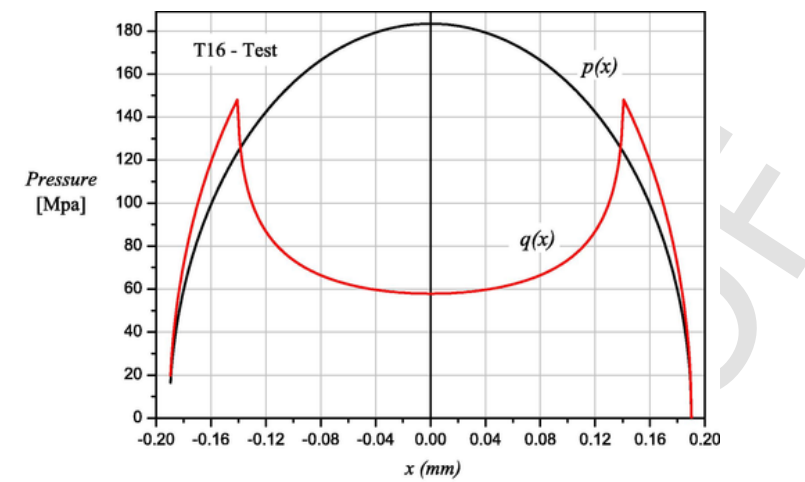

(b) T16 test

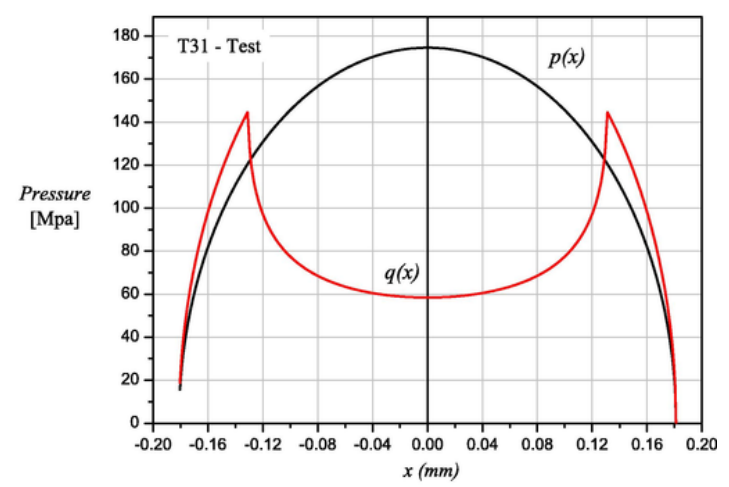

(d) T31 test

Fig. 6. Normal $p(x)$ and tangential $q(x)$ stress distributions at the contact zone. Hertz's theory, Eqs. (23)-(25).

Double Edge Notch Tension (DENT) specimens were tested in Wiersma's work in order to eliminate bending. The geometrical features of the different specimens are shown in Fig. 9 and Table 5.

Due to the lack of experimental results to construct the Kitagawa-Takahashi diagram of the material, Eq. (22), proposed by Vallellano $[15,16]$, was used with an exponent $f=2.5$.

The classical equation by Peterson [48], based on critical distance methodologies, requires use of the net stress concentration factor, which is calculated as follows:

$$
k_{t}^{\text {net }}=\frac{W_{0}}{W} k_{t}^{\text {gross }}
$$

Table 6 shows results for the net stress concentration factor obtained from FEA and Fig. 10 shows the stress-distance curves for the three wires under analysis. The gross stress concentration factor $\left(k_{t}\right)$ as well as the normalised net stress $\left(\sigma_{n e t} / \sigma_{0}\right)$ at a distance $L / 2$ for the Point Method are shown in the picture.

Table 7 shows fatigue strength estimations for the micro-scale specimens obtained with the different methods.

Reasonably good agreement of the MFEAM numerical estimations with the experimental results are obtained. However, several factors may explain the differences in the numerical predictions. First, the crack is modelled as a straight line. In addition, an approximation of the Kitagawa diagram for this material was used. Better results would be expected if the true Kitagawa-Takahashi diagram of the material were available. Another possible reason for the difference in the results is that the method assumes an uniform distribution of grains of equal size. The average grain size was set to be $10.53 \mu$ $\mathrm{m}$, but the actual size distribution of grains of the real material varies, which may explain why scatter occurred in the microscopic results. Additionally, the thickness effect is not considered in the present analysis in which the plane strain assumption was made. Despite this, the MFEAM gives the best results when compared with the other methods. Considering the boundary effect by modelling the surfaces of the solid is thought to be the main reason. Peterson's formula and the NR-model consider just the effect of the notch (the "near boundary"). The stress severity of a U-notch is given both by the notch depth $(\alpha)$ as well as the notch root $(r)$. As the notch root is the same for the three geometries, the relation of the notch depth to the net section ( $\left.W_{0} / \alpha\right)$ can be understood as a parameter to measure the influence of the boundary over the stress solution, giving an indication of how adequate it is to use semi-infinite solutions to simulate behaviour of finite components behaviour. Values of $W_{0} / \alpha=2.2,1.1$ and 0.79 for Wire 1,2 and 3 respectively, are obtained.

When $W_{0} / \alpha \rightarrow \infty$, with a less severe boundary effect, the semi-infinite or infinite models can be used and results should be accurate, in principle. Conversely, when $W_{0} / \alpha \rightarrow 0$, the behaviour of the component is strongly influenced by the effect of surface contours and as a result the methods neglecting the contour effect are less accurate. Fig. 11 shows the stress fields for the micro-scale wires and semi-infinite plates with the same U-notch geometry. Note that finite (MFEAM) and semi-infinite methods (Peterson, NR model) give similar results for the $50 \mu \mathrm{m}$ notch depth because the stress field ahead of the notch tip is practically the same for both cases. Differences arise for the other two cases. The stress fields for the finite and the semi-infinite case clearly show that the boundary effect should be taken into account. The critical distance method (PM), as shown in Table 7, predicts non-conservative results. The predicted notch fa- 


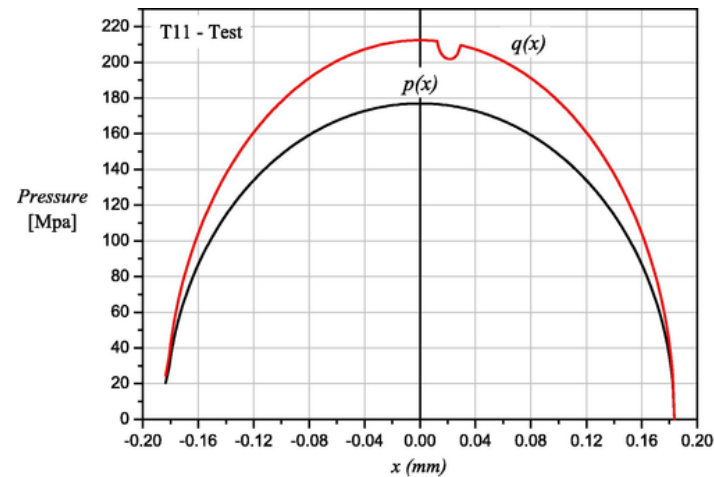

(a) T11 test

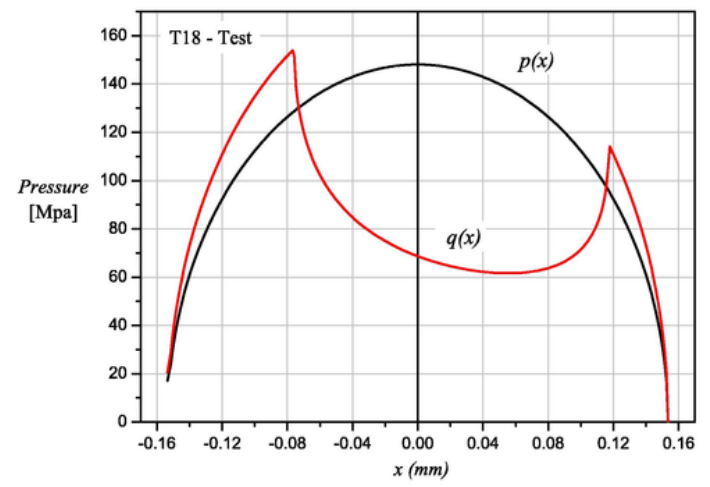

(c) T18 test

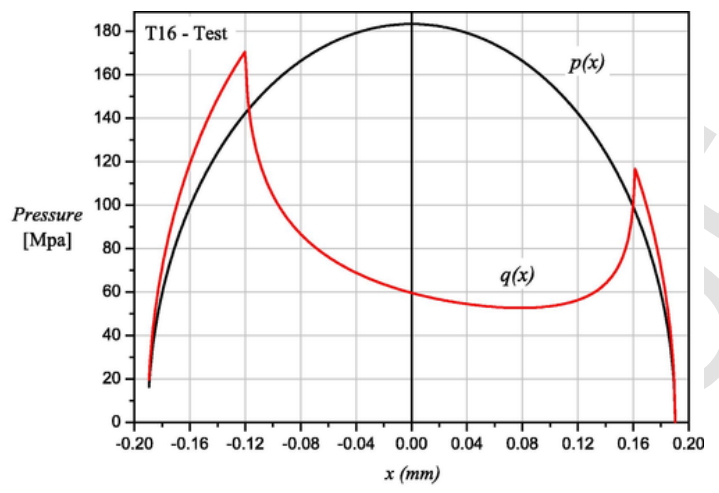

(b) T16 test

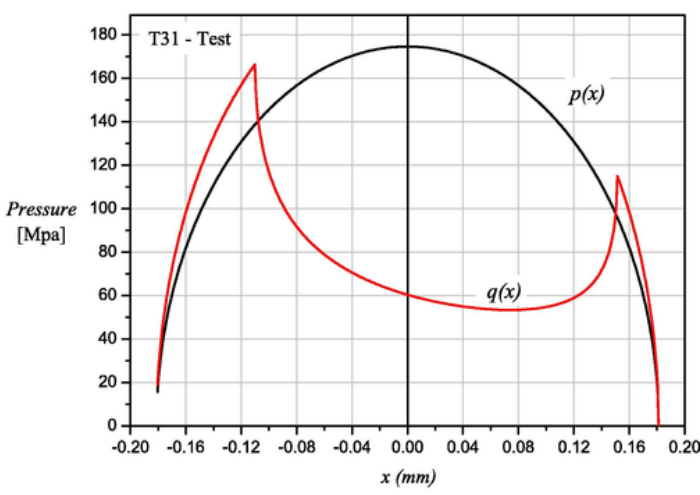

(d) T31 test

Fig. 7. Normal $p(x)$ and tangential $q(x)$ stress distributions at the contact zone considering eccentricity. Hertz's theory. Eq. (23), (29) and (30).

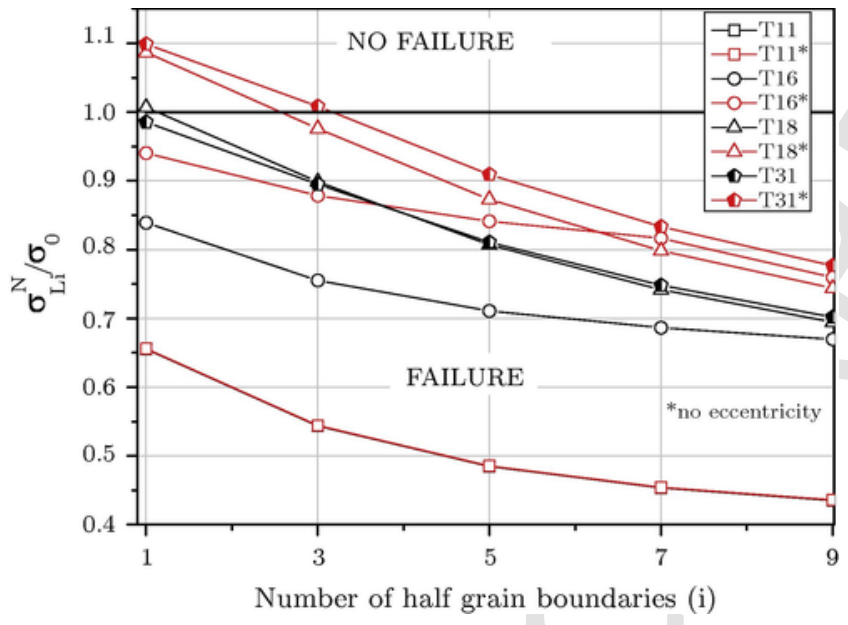

Fig. 8. MFEAM fatigue predictions for the successive microstructural barriers under fretting conditions.

tigue strengths are higher than the plain fatigue limit. These erroneous predictions are based on how the methods calculates the fatigue strength of the component:

$$
P . M \quad \sigma_{F L}^{N}=\sigma_{F L} \frac{\sigma_{n e t}}{\sigma\left(\frac{L}{2}\right)}
$$

where $\sigma_{n e t}=\frac{W}{W_{0}} \sigma_{0}$ and $\sigma\left(\frac{L}{2}\right)$ is the stress at a distance $L / 2$ form
Table 3

Comparison of MFEAM results with experimental data and other methods [43]. $R=-1$. Underlined results show discrepancy with experimental data.

\begin{tabular}{lllll}
\hline Method & T11 & T16 & T18 & T31 \\
\hline Experimental & F & F & NF & NF \\
Line method & F & NF & NF & NF \\
Point method & F & F & NF & $\underline{F}$ \\
ESM & F & F & NF & $\underline{F}$ \\
MFEAM (no eccentricity) & $\mathbf{F}$ & $\mathbf{F}$ & NF & NF \\
MFEAM (eccentricity) & $\mathbf{F}$ & $\mathbf{F}$ & $\mathbf{N F}$ & $\underline{\mathbf{F}}$ \\
\hline
\end{tabular}

F, failure; NF: No failure (before $10^{6}$ cycles); ESM, Equivalent Stress Method.

Table 4

Macroscopic material properties. Tests performed by Wiersma [45].

\begin{tabular}{lllllll}
\hline & \multicolumn{9}{c}{$K_{t h}$} \\
Material & $\sigma_{U T S}$ & $\sigma_{02}$ & $(\mathrm{MPa}$ & & & \\
& $(\mathrm{MPa})$ & $(\mathrm{MPa})$ & $\sqrt{\mathrm{m}})$ & $\sigma_{F L}(\mathrm{MPa})$ & Grain Size $(\mu \mathrm{m})$ & $R_{\sigma}$ \\
\hline AISI 316L & 754 & 396 & 7.87 & 420 & 10.53 & 0.1 \\
\hline
\end{tabular}

the notch tip. Schematically, Fig. 12 shows why the PM properly works for macro-scale components but fails to assess micro-components. In the latter case, the relation $\frac{\sigma_{\text {net }}}{\sigma\left(\frac{L}{2}\right)}$ is greater than unity, producing an overestimation of the micro-scale component fatigue strength (Eq. (33)). The results make it questionable (at least) to use PM for small components. However, acknowledging this, Taylor and Wiersma [45] succeeded in applying the method by calculating an effective critical distance, considering that for short cracks the thresh- 


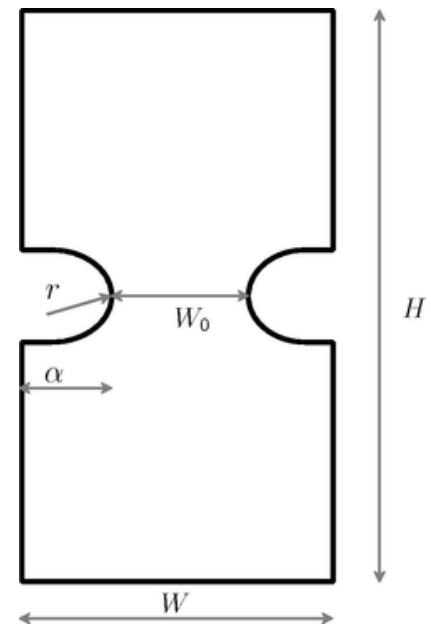

Fig. 9. Geometry of the double edge notched tension (DENT) specimens.

Table 5

Geometrical features of the micro-scale notched specimens. Rectangular cross-sectional area. The thickness $(t)$ is $90 \mu \mathrm{m}$. All dimensions in micrometers $(\mu \mathrm{m})$.

\begin{tabular}{lllll}
\hline Specimen & $\alpha$ & $r$ & $W_{0}$ & $H$ \\
\hline Wire 1 & 50 & 20 & 110 & 600 \\
Wire 2 & 100 & 20 & 110 & 600 \\
Wire 3 & 145 & 20 & 110 & 600 \\
\hline
\end{tabular}

Table 6

Stress concentration factor for Peterson's method from FEA [21].

\begin{tabular}{llll}
\hline Specimen & $K_{t}^{\text {gross }}$ & $\frac{W_{0}}{W}$ & $K_{t}^{\text {net }}$ \\
\hline Wire 1 & 4.82 & 0.52 & 2.52 \\
Wire 2 & 6.69 & 0.35 & 2.37 \\
Wire 3 & 9.82 & 0.28 & 2.70 \\
\hline
\end{tabular}

old value is lower than that for fully developed long cracks and that the value depends on the crack length. A crack in a microscopic component never reaches the constant threshold value. They proposed the following equation to calculate the value for the effective critical distance:

$$
L_{e f f}=\frac{1}{\pi}\left[\frac{\sqrt{\frac{a_{1}}{a_{1}+a_{0}}} K_{t h}}{\sigma_{F L}}\right]^{2}
$$

where $a_{1}$ is the maximum crack length and $a_{0}$ is the El Haddad's short crack parameter.

\subsection{Shot peening (SP) effect over the fatigue response of notched components}

The effect of several shot peening treatments over the fatigue strength of an aluminium Al-7075-T651 alloy is assessed in what follows. The material properties of the aluminium alloy are presented in Table 8 , in which cyclic properties are defined at $R=-1$. The microstructural model requires a mean grain size value, $D$, and the Kitagawa-Takahashi diagram for the material. The mean grain size value is estimated from Eq. (35) [49,50] and the Kitagawa-Takahashi diagram is again estimated from Eq. (22):

$$
D=\frac{2}{\pi}\left(\frac{K_{t h}}{\sigma_{F L}}\right)^{2}\left(\frac{m_{1}^{*}}{m_{\infty}^{*}}\right)^{2}
$$

A double edge V-notch specimen, Fig. 13, under reversed bending is numerically evaluated and results are compared to experimental and numerical data published by Benedetti et al. [51]. The specimen thickness is $4 \mathrm{~mm}$ and the in-plane dimensions are $W=12 \mathrm{~mm}$, $H=90 \mathrm{~mm}, r=0.5 \mathrm{~mm}, \alpha=3 \mathrm{~mm}$ and $\psi=45^{\circ}$. Just as when dealing with notch stress concentrations, it is reasonable to assume that the presence of a short crack has a negligible effect over the stress

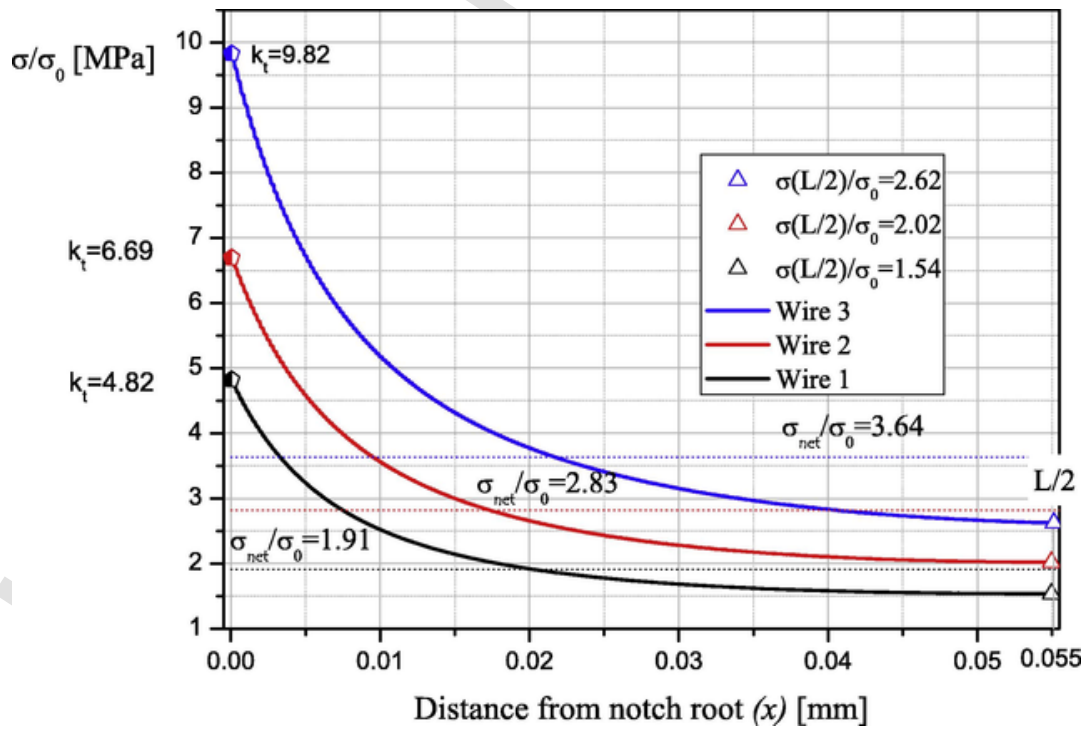

Fig. 10. Normalised stress field at the notch of the three types of DENT specimens. 
Table 7

Fatigue strength of wires. Comparisons with experimental data by Wiersma [45] and other methods. Percentage error value with respect to the experimental results are shown in parentheses. Results expressed in terms of the net section values. Positive values show conservative estimates. Values in $\mathrm{MPa}$

\begin{tabular}{llllll}
\hline & PM ( & Peterson ( & & & \\
Specimen & $\boldsymbol{L}=0.112$ & $\boldsymbol{\Psi}=0.156$ & $\begin{array}{l}\text { NR model } \\
\text { (numerical) }\end{array}$ & MFEAM & Experimental \\
\hline Wire 1 & $522(-44.9)$ & $307(14.8)$ & $306(15.0)$ & $306(15.0)$ & 360 \\
Wire 2 & $585(-64.9)$ & $273(23.0)$ & $264(25.3)$ & $321(9.6)$ & 355 \\
Wire 3 & $582(-66.4)$ & $230(34.0)$ & $239(31.0)$ & $344(1.71)$ & 350 \\
\hline
\end{tabular}

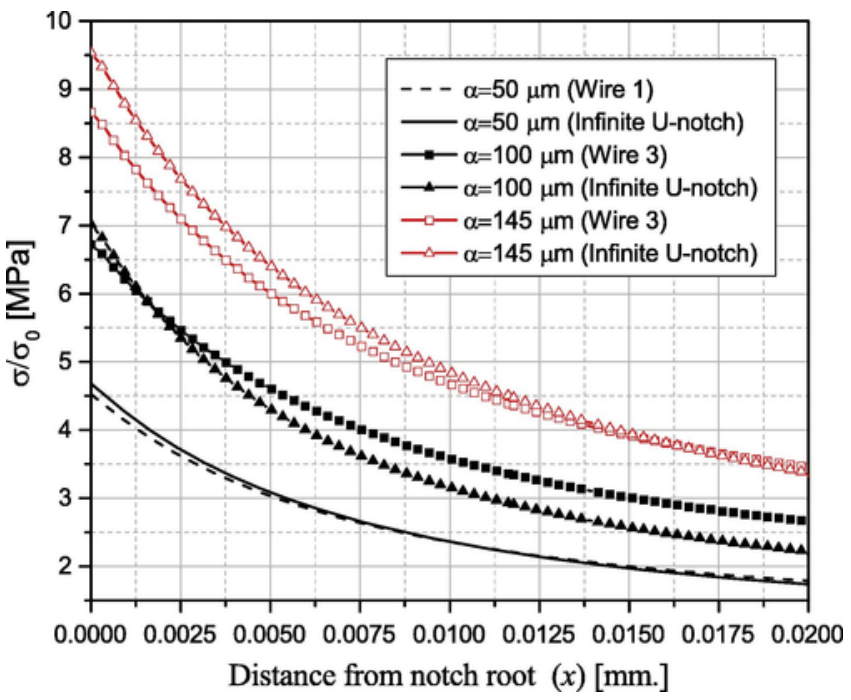

Fig. 11. Stress field at the notch root in infinite and finite solids.
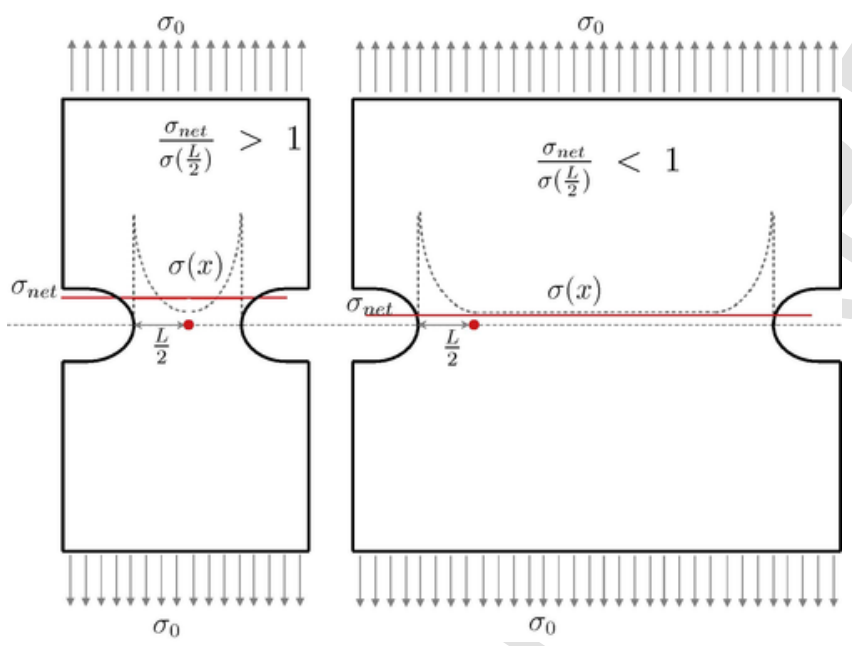

Fig. 12. Schematic representation of PM's inability to assess micro-scale components

fields produced by the shot-peening treatment, thus the superposition principle can be used. As a result, it is possible to superimpose the residual stress field $\left(\sigma^{R S}\right)$ in an application of Bueckner's theorem [25]. The residual stress gradient $\left(\sigma^{R S}\right)$ produced by shot peening was obtained by means of X-RD (X-ray Diffraction) measurements on plain specimens [51].

Thus, the effect of residuals stresses is straightforwardly included in the MFEAM, Eq. (1) (DDT problem), as follows:
Table 8

Physical and mechanical properties of Al-7075-T651 alloy [51]

\begin{tabular}{lllll}
\hline & & & $\begin{array}{l}K_{t h} \\
(\mathrm{MPa}\end{array}$ \\
$\begin{array}{l}\text { Young's } \\
\text { Modulus E } \\
(\mathrm{GPa})\end{array}$ & $\begin{array}{l}\text { Plain fatigue limit } \sigma_{F L} \\
(\mathrm{MPa})\left(5 \times 10^{6} \text { cycles }\right)\end{array}$ & $\begin{array}{l}\text { Poisson's } \\
\text { ratio }\end{array}$ & $\begin{array}{l}\sqrt{\mathrm{m}} \\
\text { size } D \text {, Eq. (35) } \\
\mu \mathrm{m})\end{array}$ \\
\hline 73 & 290 & 0.3 & 3 & 7.1 \\
\hline
\end{tabular}

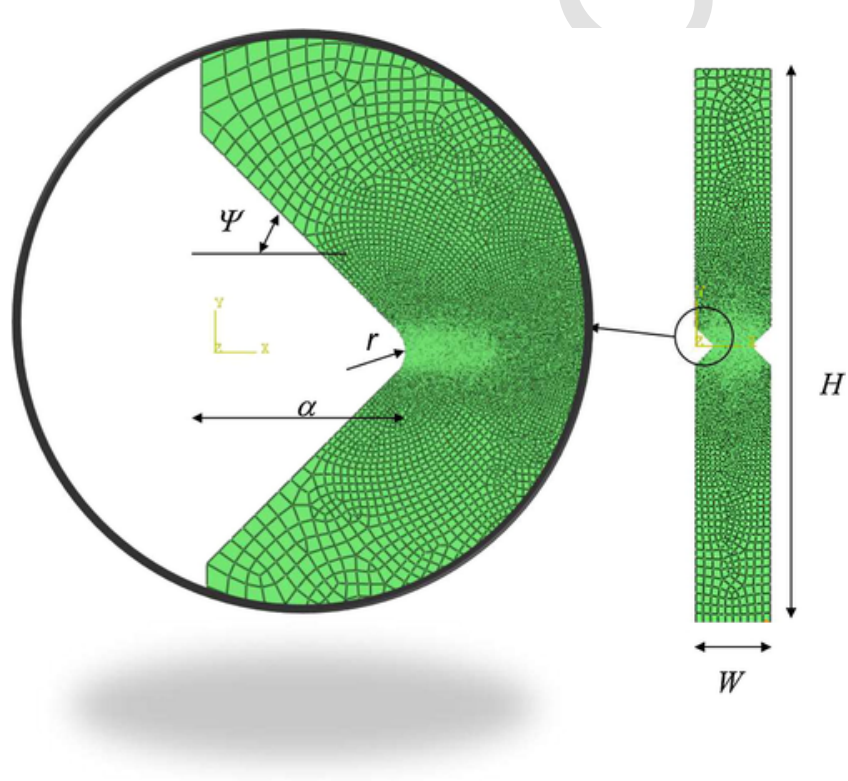

Fig. 13. Finite element mesh and parametric dimensions of the shot-peened specimen undergoing reverse bending.

$\int_{-c}^{c} f(\xi) K(x, \xi) d \xi+\frac{\sigma(x)-\sigma_{j}(x)+\sigma^{R S}(x)}{A}=0 \quad j=1,2,3$

Consider the initial residual stress profiles for the CE-B120, CE-Z425, CE-Comb conditions [51]. Fig. 14 shows the initial residual stress field produced by the different shot peening treatments on the

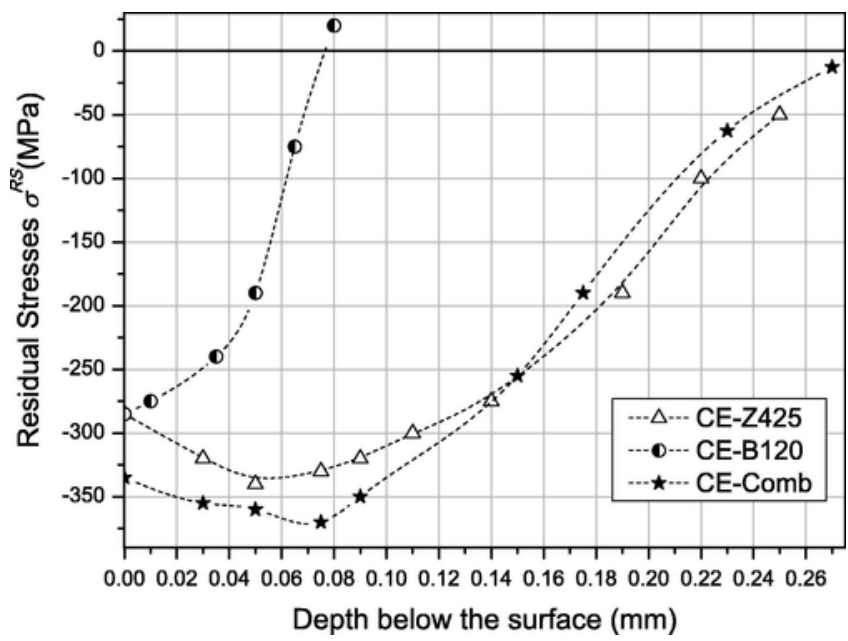

Fig. 14. Residual stress profiles created by shot-penning [51]. 
Al-7065-T651 alloy. In this section, the influence of a shot-peened surface over the notch fatigue strength is evaluated.

Although the initial stress state is later relaxed during the cyclic loading of the specimen, the first approach to the problem of the present work involves only the initial residual stresses, without taking into account the progressive stress relaxation. Fig. 15 presents the results for the external stresses needed to overcome the specimen's first 10 microstructural barriers. The residual stress profile produced by the different shot-penning treatments improves the notch fatigue strength, which is consistent with the experimental observations.

Fig. 16 shows that the results obtained with the proposed method are in excellent agreement with the experimental data for as-received, CE-B120 and CE-Comb conditions, providing conservative estimates with differences with experimental results of $13.5 \%, 0.76 \%$ and $4.56 \%$, respectively. For the case of using the CE-Z425 residual stress profile in the assessment, estimations were non-conservative and the difference is greater than $65 \%$. Similar trends are observed in the results in comparison with those reported by Benedetti et.al [51] using the extended CDM approach. The proposed approach captures the beneficial effect of shot peening treatment for 2D notched specimens.

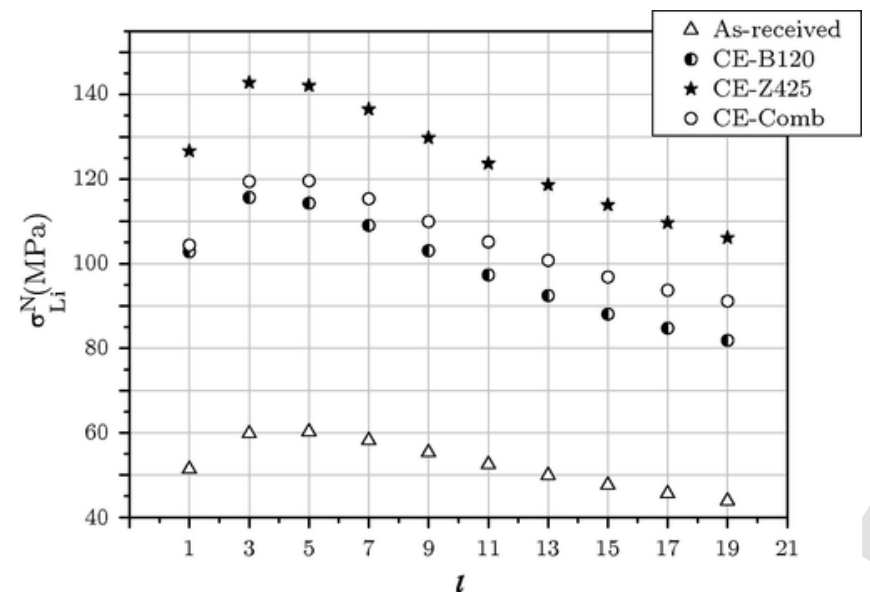

Fig. 15. Minimum applied stress required to overcome the successive barriers for the four different shot-peening treatments.

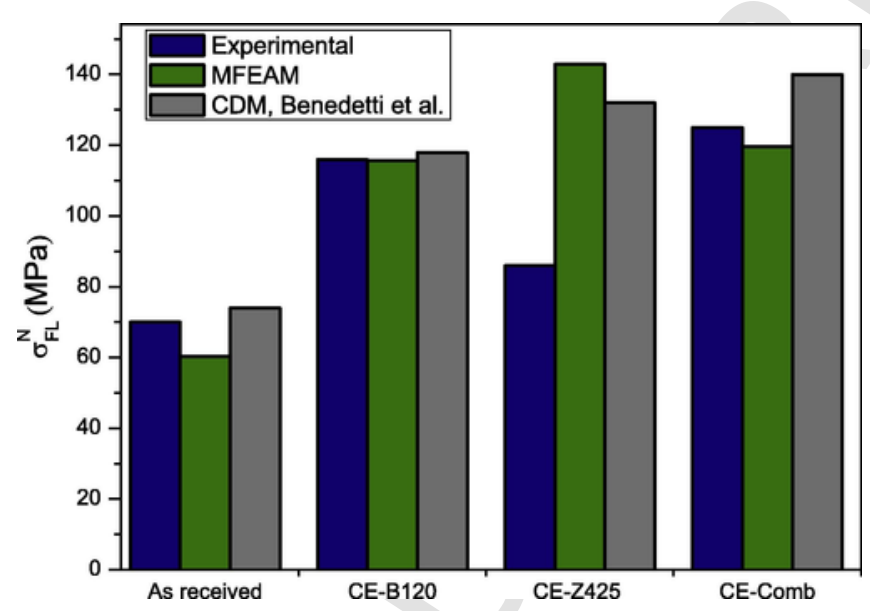

Fig. 16. MFEAM Fatigue strength predictions considering different shot-peening initial residual stresses.

\section{Conclusions}

In this paper, as an extension to the numerical work done by Chaves and Navarro [17,18], a microstructural model has been implemented into the Finite Element Alternating Method framework, here termed the Microstructural Finite Element Alternating Method (MFEAM).

The method relies on the Schwarz-Neumann alternating method $[32,33]$. The final solution of the problem is found by the iterative computation of the FEM solution for a finite body without a crack and the microstructural analysis for a crack in an infinite polycrystalline body (using DDT). In the present paper, for validation purpose, the MFEAM has been applied to (I) small components, those in which the effect of the contours on the fatigue crack propagation behaviour is significant; (II) problems including residual stress profiles and; (III) a fretting fatigue example problem. Results are consistent with reported values in the literature, suggesting that the method proposed is attractive and useful for fatigue analysis of components under more realistic loading conditions.

The advantage of the MFEAM is that it relies on the Finite Element Method (FEM), which is a flexible, widely used tool for solving boundary value problems, in combination with the Distributed Dislocation Technique (DDT), which provides an accurate modelling of crack tip singularities. The NR short crack microstructural model considers the interaction of the crack with the successive microstructural barriers. Advantages of the present method are that it leads to a reduction of costs, both computational and manpower, since it allows consideration of the interaction of the crack with the barriers without the need for re-meshing. The method does not require the explicit formulation of the equilibrium equations of dislocations for any particular geometry. Only the fundamental solution for the infinite plane is required. This increases the flexibility of the method and facilitates the solution of problems involving bodies of arbitrary geometry with no additional complications.

\section{Acknowledgement}

The authors would like to thank the Spanish Ministry of Education for its financial support through grant DPI2014-56904-P.

\section{References}

[1] A.W. Thompson, W.A. Backofen, The effect of grain size on fatigue, Acta Metall 19 (7) (1971) 597-606.

[2] S. Pearson, Fatigue crack closure under cyclic tension, Eng Fract Mech 7 (1975) 235-247.

[3] K.J. Miller, The two thresholds of fatigue behaviour, Fatigue Fract Eng Mater Struct 16 (9) (1993) 931-939.

[4] S. Suresh, R.O. Ritchie, Propagation of short fatigue cracks, Int Met Rev 29 (6) (1984) 445-476.

[5] R.O. Ritchie, J. Lankford, Small fatigue cracks, The Metallurgical Society of the American Institute of Mining, Metallurgical, and Petroleum Engineers, Warrendale, PA, 1986.

[6] P.D. Hobson, Formulation of a crack growth equation for short cracks, Fatigue Fract Eng Mater Struct 5 (1982) 323-327.

[7] K.S. Chan, J. Lankford, A crack tip model for the growth of small fatigue cracks, Scr Metall 17 (1983) 529-532.

[8] E.R. de los Rios, A. Navarro, Consideration of grain orientation and work hardening on short-fatigue-crack modelling, Philos Mag A 61 (1990) 435-439.

[9] A. Navarro, E.R. de los Rios, Short and long fatigue crack growth: a unified model, Philos Mag A 57 (1988) 37-42.

[10] A. Navarro, E.R. de los Rios, An alternative model of the blocking of dislocations at grain boundaries, Philos Mag A 57 (1988) 37-42.

[11] A. Navarro, E.R. de los Rios, Fatigue crack growth by successive blocking of dislocations, Proc Math Phys Sci 437 (1992) 375-390. 
[12] K. Hussain, E.R. de los Rios, A. Navarro, A two-stage micromechanics model for short fatigue cracks engineering fracture mechanics, Eng Fract Mech 44 (1993) 425.

[13] K. Tanaka, T. Mura, A micromechanical theory of fatigue crack initiation from notches, Mech Mater 1 (1) (1982) 63-73.

[14] M.D. Chapetti, Prediction of the fatigue limit of blunt-notched components, Int J Fatigue 23 (1) (2001) 171-176.

[15] C. Vallellano, A. Navarro, A.J. Dominguez, Fatigue crack growth threshold conditions at notches. Part 1: Theory, Fatigue Fract Eng Mater Struct 23 (2000) $113-121$

[16] C. Vallellano, A. Navarro, A.J. Dominguez, Fatigue crack growth threshold conditions at notches. Part 2: Generalization and application to experimental results, Fatigue Fract Eng Mater Struct 23 (2000) 123-128.

[17] V. Chaves, A. Navarro, Application of a microstructural model for predicting notch fatigue limits under mode I loading, Int J Fatigue 31 (2009) 943-951.

[18] V. Chaves, A. Navarro, Fatigue limits for notches of arbitrary profile, Int J Fatigue 48 (2013) 68-79.

[19] T.S. Jacobs, J. Won, E.C. Gravereaux, P.L. Faries, N. Morrissey, V.J. Teodorescu, et al., Mechanical failure of prosthetic human implants: a 10-year experience with aortic stent graft devices, J Vasc Surg 37 (1) (2003) 16-26.

[20] R.B. Waterhouse, T.C. Lindley, Fretting fatigue, ESIS Publication 18, Mechanical Engineering Publication, 1994

[21] N.O. Larrosa, Iterative microstructural model for the prediction of fatigue failure in finite components, [Ph.D. thesis] University of Seville, 2012

[22] N.O. Larrosa, A. Navarro, V. Chaves, Calculating fatigue limits of notched components of arbitrary size and shape with cracks growing in mode I, Int J Fatigue 74 (2015) 142-155.

[23] M.J. Lin, D. Hills, Stress intensity factors for cracks emanating from a semicircular notch in a half-plate, J Strain Anal Eng Des 31 (1996) 433-439.

[24] D.N. Dai, Modelling cracks in finite bodies by distributed dislocation dipoles, Fatigue Fract Eng Mater Struct 25 (1) (2002) 27-39.

[25] H.F. Bueckner, The propagation of cracks and the energy of elastic deformations, J Appl Mech 80 (1958) 1225-1230.

[26] D. Nowell, D. Dini, P. Duõ, Stress analysis of V-notches with and without cracks, with application to foreign object damage, J Strain Anal Eng Des 38 (5) (2003) 429-441.

[27] N.O. Larrosa, A dislocation based method using generative algorithms to mode notch geometries: determination of mode I SIFs, Eng Fract Mech 127 (2014) 327-335.

[28] N.O. Larrosa, M. Treifi, R.A. Ainsworth, Rapid parametric analysis of SEN(T) specimens using algorithmic modelling: evaluation of strain energy density and notch stress intensity factors, Mater Des 85 (2015) 771-777.

[29] Muskhelishvili NI. Singular integral equations. P. Noordhoff, Groningen (reprinted by Dover Publications Inc, 1992 and 2008); 1953

[30] R.A. Smith, K.J. Miller, Prediction of fatigue regimes in notched components, Int J Mech Sci 20 (1978) 201-206.

[31] H. Kitagawa, S. Takahashi, Application of fracture mechanics to very small cracks, In: International conference of mechanical behaviour of materials (ICM2), 1976, pp. 627-631.
[32] I.S. Sokolnikoff, The mathematical theory of elasticity, McGraw-Hill, New York, 1956.

[33] L.V. Kantorovich, V.I. Krylov, Approximate methods of higher analysis, Interscience, New York, 1958.

[34] D.A. Hills, P.A. Kelly, D.N. Dai, A.M. Korsunsky, Solution of cracks problems, the distributed dislocation technique, Kluwer Academic Publishers, 1996.

[35] ABAQUS V. 6.13, Reference Manual, Simulia, Dassault Systemes; 2013.

[36] G.P. Wright, J.J. O'Connor, The influence of fretting and geometric stress concentrations on the fatigue strength of clamped joints, Proc Inst Mech Eng 186 (1) (1972) 827-835.

[37] Johnson KL, O'Connor JJ. Mechanics of fretting. In: Applied mechanics convention newcastle 14-17 April 1964. Paper 11 Institute of Mechanical Engineering, London; 1964

[38] Fouvry S, Kapsa P, Vincent L. Multiaxial fatigue analysis of fretting contact taking into account the size effect, in fretting fatigue: current technology and practices. In ASTM special technical publication; 2000. p. 167-82.

[39] K. Dang Van, M.H. Maitournam, On a new methodology for quantitative modeling of fretting fatigue, In: Fretting fatigue: current technology and practices, 2000 , pp. 538-552.

[40] J.A. Araujo, D. Nowell, The effect of rapidly varying contact stress fields on fretting fatigue, Int J Fatigue 24 (7) (2002) 763-775.

[41] S. Naboulsi, S. Mall, Fretting fatigue crack initiation behaviour using process volume approach and finite element analysis, Tribol. Int. 36 (2) (2003) 121-131. cited By (since 1996) 17.

[42] M. Ciavarella, G. Demelio, D.A. Hills, Fretting fatigue problems associated with almost flat contacts, In: Gruppo Italiano Frattura, Convegno IGF XIII, 1997

[43] C. Vallellano, J. Dominguez, A. Navarro, Influence of R ratio and stick zone eccentricity on the prediction of the fretting fatigue limit with spherical contact, Int J Fatigue 29 (7) (2007) 1208-1219.

[44] D. Taylor, Geometrical effects in fatigue: a unifying theoretical approach, Int J Fatigue 21 (12) (1999) 413-420.

[45] S.A. Wiersma, The effect of stress concentrations on fatigue and fracture of 316L stainless steel micro-scale components, [Ph.D. thesis] Trinity College Dublin, 2004

[46] S. Wiersma, F. Dolan, D. Taylor, Fatigue and fracture in materials used for mi cro-scale biomedical components, Bio-Med Mater Eng 16 (2) (2006) 137-146.

[47] S. Wiersma, D. Taylor, Fatigue of materials used in microscopic components, Fatigue Fract Eng Mater Struct 28 (12) (2005) 1153-1160.

[48] R.E. Peterson, Notch sensitivity, McGraw-Hill, 1959

[49] A. Navarro, E.R. de los Rios, A model for short fatigue crack propagation with an interpretation of the short-long crack transition, Fatigue Fract Eng Mater Struct 10 (1987) 169-186.

[50] V. Chaves, Modelo microestructural para la predicciõn de fallo por fatiga en entallas, [Ph.D. thesis] Universidad de Sevilla, 2006.

[51] M. Benedetti, V. Fontanari, C. Santus, M. Bandini, Notch fatigue behaviour of shot peened high-strength aluminium alloys: experiments and predictions using a critical distance method, Int J Fatigue 32 (2010) 1600-1611. 